\title{
EVALUATION OF SYNAPTOPHYSIN EXPRESSION IN UNICYSTIC AND MULTICYSTIC AMELOBLASTOMA OF THE JAW: AN IMMUNOHISTOCHEMICAL STUDY
}

\author{
Elsayed Mohamed Deraz*
}

\begin{abstract}
Objective: Ameloblastoma is a benign odontogenic tumor of epithelial origin that exhibits a locally aggressive behavior with a classic view about neural crest origin of this tumor. The objective of the current study was to evaluate the expression of synaptophysin (a membrane glycoprotein of presynaptic vesicles) by odontogenic epithelial cells in ameloblastoma and to verify the usefulness of synaptophysin as a neuroectodermal marker in ameloblastoma.
\end{abstract}

Material and methods: Paraffin-embedded tissue blocks of 40 cases of ameloblastoma were used. These cases include unicystic and multicystic types ( 20 cases each). The specimens were stained with monoclonal antibody recognizing synaptophysin molecule by using immunohistochemistry.

Results: In unicystic ameloblastoma, synaptophysin expression was seen in (87.5\%) of luminal variant and in $(91.6 \%)$ of mural ameloblastoma cases. Follicular ameloblastoma showed positive expression of synaptophysin in all cases $(100 \%)$, whereas plexiform type exhibited positivity in $(88.8 \%)$. The expression of synaptophysin in both unicystic and multicystic ameloblastoma was predominantly membranous with sporadic cytoplasmic expression. This expression was detected in ameloblast and stellate reticulum-like cells in both unicystic and multicystic ameloblastoma.

Conclusion: Expression of synaptophysin in both unicystic and multicystic ameloblastoma may prove the usefulness of synaptophysin as a valuable neuroectodermal marker in ameloblastoma.

KEYWORDS: Synaptophysin, Ameloblastoma, Immunohistochemistry

\section{INTRODUCTION}

Ameloblastomas are benign epithelial odontogenic tumors of the jaw bones that have the potential to grow into large size with bone deformity and are characterized by peculiar clinical behavior $^{1,2}$. They are classified as unicystic, multicystic and peripheral (extraosseous) types ${ }^{1}$.

The unicystic ameloblastoma refers to the cystic lesion with ameloblastic epithelial lining accompanied by luminal, intraluminal or mural tumor

\footnotetext{
* Lecturer, Department of Oral Pathology, Faculty of Dentistry, Tanta University, Egypt
} 
proliferation ${ }^{3}$. Multicystic/solid ameloblastoma is the most clinically significant odontogenic tumor which is often locally invasive ${ }^{4}$. Microscopically, a variety of histopathologic types are shown with follicular and plexiform predominating ${ }^{4,5}$. The potential sources that take part in forming ameloblastoma include the stratified squamous epithelium of oral cavity, remnants of dental lamina, enamel organ of the developing tooth and the lining of odontogenic cysts particularly dentigerous cyst ${ }^{1}$.

The participation of neural crest cells in the process of odontogenesis is recognized and the tooth is well known to be a derivative of the neural crest $^{6}$. During this process, the neural crest cells may impart few of their characteristics to oral epithelium via specific signal transductions ${ }^{7}$. Therefore, the basal cell of oral epithelium may have the potential to proliferate and thus becoming a source for ameloblastoma ${ }^{8}$. Moreover, it was demonstrated that the dental lamina has its origin from the neuroectoderm ${ }^{6}$ and ameloblastoma may originate from the dental lamina rests ${ }^{1}$.

Neuroectodermal markers are numerous and include neuron-specific enolase (NSE), cluster of differentiation 99 (CD99), chromogranin, glial fibrillary acidic protein (GFAP) and synaptophysin' ${ }^{9}$.

Among these, synaptophysin is a $38 \mathrm{kDa}$ membrane glycoprotein of presynaptic vesicles that in human is encoded by SYP gene ${ }^{10}$. It presents in human neuroendocrine cells that is why it is used as a marker of neuroendocrine differentiation in tumors ${ }^{10,11}$.

Synaptophysin expressed in a variety of neoplasms of both neural and epithelial types. It was shown to be positive in ganglioneuroblastoma ${ }^{12}$, medulloblastoma ${ }^{13}$ and neuroblastoma ${ }^{14}$. In addition, synaptophysin immunostaining was detected in pancreatic neoplasms ${ }^{15}$. Moreover, the occurrence of neuroendocrine differentiation in breast cancers was demonstrated by the expression of synaptophysin and other neuroendocrine markers ${ }^{16}$.
In the literature, however, there are few reports regarding the expression of synaptophysin in ameloblastoma of the jaw. Therefore, this study was undertaken to evaluate the expression of synaptophysin in unicystic and multicystic ameloblastoma by immunohistochemistry and to verify the usefulness of synaptophysin as a neuroectodermal marker for ameloblastoma.

\section{MATERIALS AND METHODS}

\section{Selection of cases}

In the current study, 40 archival ameloblastoma cases were selected from Oral Pathology Department, Faculty of Dentistry, Tanta University after an acceptance from the head of department. These cases included unicystic and multicystic types (20 cases each). Unicystic ameloblastoma were histopathologically subdivided into luminal (8 cases) and mural type (12 cases). In multicystic ameloblastoma; follicular and plexiform subtypes were involved (11 and 9 cases respectively).

\section{Hematoxylin and eosin staining}

All samples were fixed in $10 \%$ formalin and routinely processed and embedded in paraffin. Serial sections cut at $4 \mu \mathrm{m}$ were used for hematoxylin and eosin (H \& E) staining.

\section{Immunohistochemical staining}

Other $4 \mu$ m-thick sections were cut and received on positive-charge slides for immunohistochemical staining. Tissue sections were deparaffinized in xylene and rehydrated in descending grades of ethanol, Blocking of endogenous peroxidase activity was done by methanol containing $0.3 \% \mathrm{H}_{2} \mathrm{O}$ for 30 minutes. Microwaving was performed for antigen retrieval using a citrate phosphate buffer $(\mathrm{pH}$ 6.0) and then the sections were incubated with the primary antibody at $4^{\circ} \mathrm{C}$ overnight. The immunohistochemical staining was carried out by monoclonal mouse anti-human synaptophysin (Dako) at dilution 
of 1:100. After incubation with secondary antibody and for detection of the reaction, diaminobenzidine (DAB) was used. The sections were then counterstained by hematoxylin and dehydrated in ascending grades of ethanol. Finally, the slides were mounted and examined under light microscope. Negative control staining was performed by omitting primary antibody. Synaptophysin was considered positive if over than $10 \%$ of tumor cells showed strong or diffuse staining.

\section{Statistical analysis}

All data were collected, tabulated and statistically analyzed. A p value $<0.05$ is required for assessing the significance.
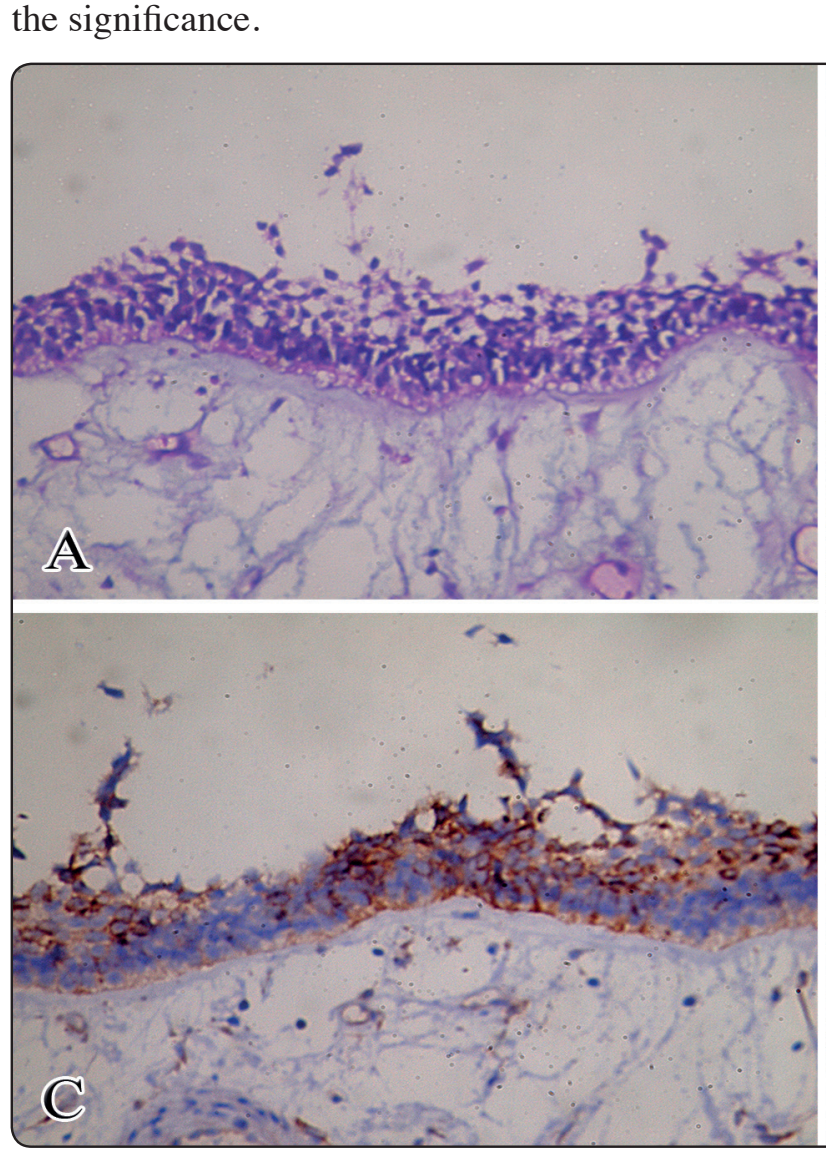

\section{RESULTS}

In this study, more than $90 \%$ (37/40 cases) of ameloblastoma studied showed a positive reaction to synaptophysin (Table 1).

\section{Synaptophysin immunoreactivity in unicystic ameloblastoma}

Unicystic ameloblastoma was subclassified into two groups; luminal (8 cases) and mural (12 cases), (Table 1). In luminal variant, the tumor is confined to the luminal surface of the cyst. It consists of a fibrous cyst wall with a lining that contains ameloblastic epithelium and overlying loosely cohesive stellate reticulum-like cells (Fig. 1A). In mural ameloblastoma, the fibrous wall of the cyst

Fig. (1) (A) and (B) Unicystic ameloblastoma; luminal type (A) exhibits a fibrous cyst wall with a lining consisting of ameloblastlike cells with reverse nuclear polarity and an overlying stellate reticulum-like cells. Mural ameloblastoma (B) showing a fibrous wall infiltrated by follicular ameloblastoma with a lining similar to luminal variant (H\&E, (A) x40, (B) x20). (C) and (D) Synaptophysin immunostaining in luminal (C) and mural ameloblastoma (D). Both ameloblast and stellate reticulum-like cells in the lining and the ameloblastic follicle in connective tissue wall show positivity for synaptophysin. The expression is mostly membranous with sporadic cytoplasmic expression (IHC, (C) x40, (D) x20) 
is infiltrated by ameloblastic epithelium in form of follicular or plexiform pattern (Fig. 1B).

Immunostaining in unicystic ameloblastoma was observed in both luminal epithelial lining and ameloblastic nests in the fibrous wall of the cyst (Fig. 1C\& D). In luminal variant, synaptophysin was seen in $87.5 \%$ ( $7 / 8$ cases). Its expression was predominantly membranous with sporadic cytoplasmic expression (Fig. 1C) and the expression was recognized in both ameloblast-like cells and the overlying stellate reticulum-like cells.

Mural type exhibited a positive reaction to synaptophysin in $91.6 \%$ (11/12 cases). Its expression was detected in both luminal epithelial lining and the infiltrating ameloblastic follicles in the fibrous wall
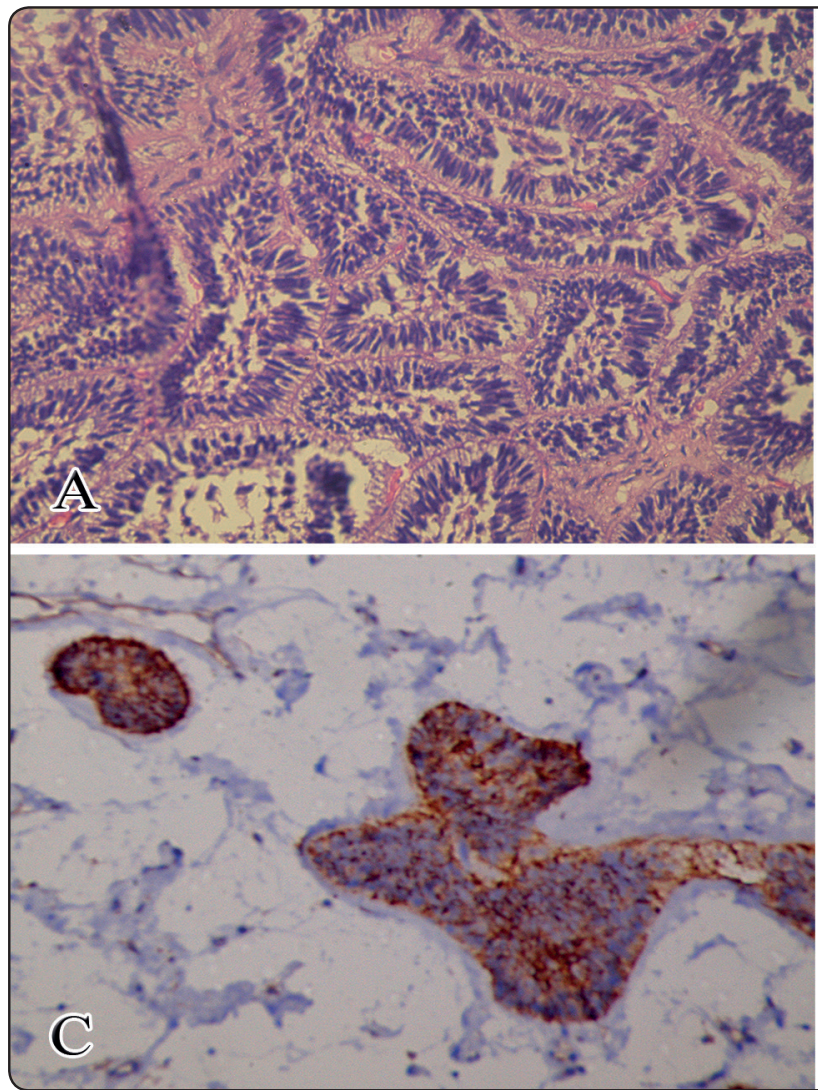

of the cyst (Fig. 1D). The expression was mostly membranous with cytoplasmic expression in some cells of both lining and ameloblastic nests.

\section{Synaptophysin immunoreactivity in multicystic ameloblastoma}

Multicystic ameloblastoma was subdivided into: follicular (11 cases) and plexiform (9 cases). Follicular subtype showed nests which consisted of outer columnar ameloblast-like cells and inner stellate reticulum-like cells (Fig. 2A), whereas the plexiform type exhibited a proliferation of the tumor cells with a reticular pattern (Fig. 2B).

All cases of follicular ameloblastoma demonstrated a positive immunostaining to

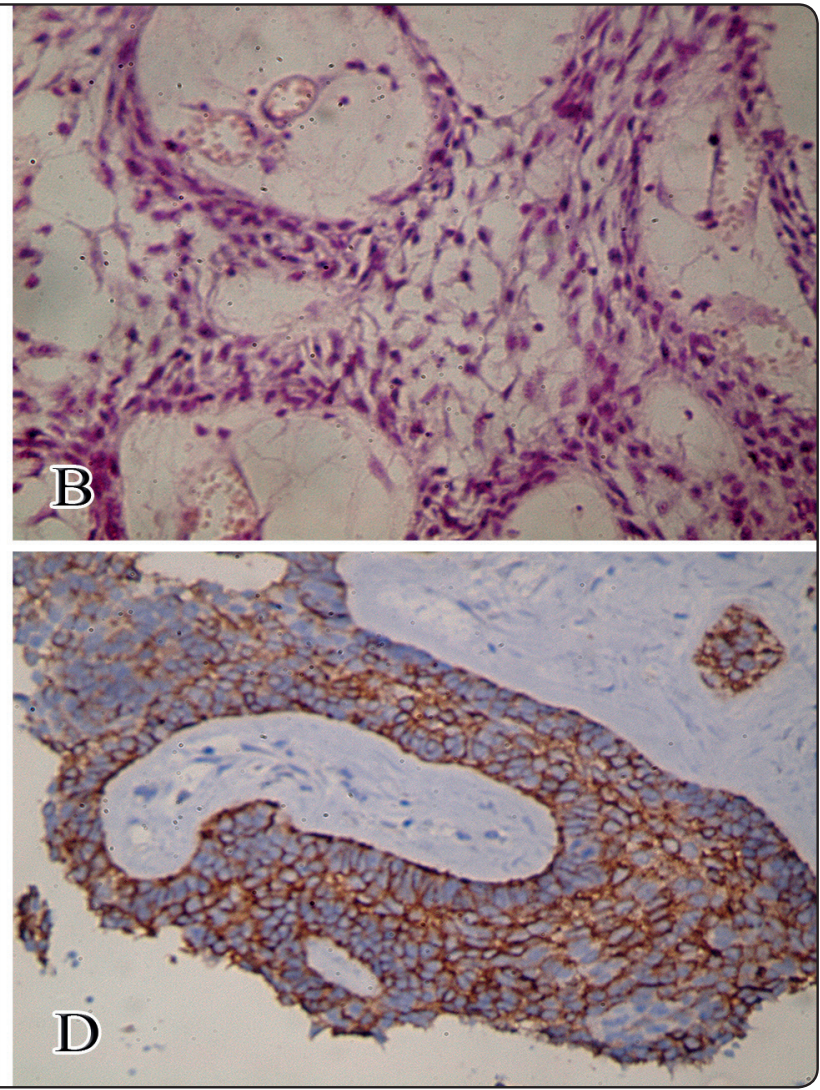

Fig. (2) (A) and (B) Multicystic ameloblastoma; follicular type (A) reveals islands of odontogenic epithelium with columnar peripheral cells with reverse polarity. The central areas of the islands exhibit stellate reticulum-like cells. Plexiform type (B) showing anastomosing sheets of odontogenic epithelium consisting of ameloblast and stellate reticulum-like cells. (H\&E, (A) $\mathrm{x} 40$, (B) $\mathrm{x} 40$ ). (C) and (D) Immunoreactivity of synaptophysin in multicystic ameloblastoma. The expression in both (C) and (D) are shown in almost all tumor cells in a predominant membranous pattern with few cells showing cytoplasmic expression. (IHC, (C) x40, (D) $\mathrm{x} 40$ ) 
synaptophysin (11/11). The expression was seen in both outer ameloblast-like cells and the inner stellate reticulum-like cells in a membranous and cytoplasmic distribution (Fig. 2C). Immunoreactivity for synaptophysin was shown in $88.8 \%$ (8/9 cases) of plexiform ameloblastoma. The expression was detected in all tumor cells with prominent membranous pattern (Fig. 2D). The number of cases studied and the percentage of synaptophysin positive cases were shown in Table 1 . The results were significant with $\mathrm{p}$ value $<0.05$.

TABLE (1) Immunoreactivity of synaptophysin in ameloblastoma

\begin{tabular}{|c|c|c|}
\hline Ameloblastomas & $\begin{array}{c}\text { Number of } \\
\text { cases }\end{array}$ & $\begin{array}{c}\text { Synaptophysin } \\
+(\%)\end{array}$ \\
\hline Unicystic (luminal) & 8 & $7(87.5)$ \\
\hline Unicystic (mural) & 12 & $11(91.6)$ \\
\hline Multicystic (follicular) & 11 & $11(100)$ \\
\hline Multicystic (plexiform) & 9 & $8(88.8)$ \\
\hline
\end{tabular}

\section{DISCUSSION}

Ameloblastoma is one of the benign odontogenic epithelial tumors that exhibits a locally aggressive behavior with the classic view about the neural crest origin of the cells giving this tumor ${ }^{17}{ }^{18}$. It is originated from dental lamina remnants, the enamel organ in development, epithelial lining of odontogenic cysts or from the cells of the basal layer of oral mucosa ${ }^{1}$.

Synaptophysin is an integral membrane glycoprotein that occurs in presynaptic vesicles of neurons and expressed in several neoplasms of both neural and epithelial types ${ }^{11}$. There were few reports regarding the expression of synaptophysin in ameloblastoma. This study aimed to evaluate the expression of synaptophysin in ameloblastoma both unicystic and multicystic types.
In this study, synaptophysin expression was detected in more than $90 \%$ of ameloblastoma cases including unicystic and multicystic variants. The expression was revealed in ameloblast and stellate reticulum-like cells in predominantly membranous pattern with sporadic cytoplasmic expression.

A previous study showed almost similar findings in unicystic ameloblastoma in which both luminal and infiltrating nests exhibited positivity for CD56 (a protein associated with nervous system development) ${ }^{19}$. Other reports demonstrated the expression of several neuroectodermal markers in ameloblastoma. In one study done on thirty two cases of ameloblastoma, immunoreactivity to CD99, synaptophysin, S100 and NSE was seen giving a link between neuroectoderm and ameloblastoma ${ }^{20}$. Moreover, another study using NSE, synaptophysin and CD99 demonstrated a potential for basal cells of the oral ectoderm particularly that overlying the bone of the jaw to give rise to odontogenic cysts and neoplasms ${ }^{8}$.

It has been suggested that ameloblastoma arise from remnants of dental lamina. Therefore, the results of this study and others may be explained by the thought that dental lamina originated from the neuroectoderm ${ }^{6}$. In addition, the odontogenic epithelium of ameloblastoma may have the potential to express neuroectodermal signals after years from completing odontogenesis process ${ }^{20}$. Accordingly, synaptophysin was shown to be positive in almost all cases of ameloblastoma in the current study.

On the other hand, it was noted that few cases of ameloblastoma in this study did not show immunoreactivity to synaptophysin. This finding may be attributed to the decalcification process and probably to the small size of the specimens as well. This feature showed that although synaptophysin has been detected in a high percentage of ameloblastoma both unicystic and multicystic types, this reaction can be avoided and a few cases of ameloblastoma may be negative for synaptophysin. 
In conclusion, the expression of synaptophysin in ameloblastoma supports the relationship between tumorigenesis of this neoplasm and neural crest cells. Moreover, synaptophysin may be a valuable neuroectodermal marker of ameloblastoma. Additional studies with a wide sample range and more advanced methodology are recommended to support these findings.

\section{REFERENCES}

1. Neville BW (2002). Oral and Maxillofacial Pathology, $3^{\text {rd }}$ ed. WB Saunders

2. Gumgum S, Hosgoren B (2005). Clinical and radiologic behavior of ameloblastoma in 4 cases. J Can Dent Assoc 71(7); 481-484

3. Gupta N, Sexena S, Rathod VC, Aggarwal P (2011). Unicystic ameloblastoma of the mandible. J Oral Maxillofac Pathol 15(2); 228-231

4. Fulco GM, Nonak CF, Souza LB, Miquel MC, Pinto LP (2010). Solid ameloblastomas-retrospective clinical and histopathologic study of 54 cases. Braz J Otorhinolaryngol 76(2); 172-177

5. Hertog D, Bloemena E, Aartman HA, Van-der-Waal I (2012). Histopathology of ameloblastoma of the jaws; some critical observations based on a 40 years single institution experience. Med Oral Patol Oral Cir Bucal 17(1); e76-82

6. Ten Cate AR (1989). Oral Histology. $3^{\text {rd }}$ ed. CV Mosby, St Louis

7. Jowett S, Vainio S, Ferguson MW, Sharpe PT, Thesleff I (1993). Epithelial -ectomesenchymal interactions are required for MSX 1 and MSX 2 gene expression in the developing murine molar tooth. Development 117; 461470

8. Nagumalini BR, Suneela S, Narayan TV, Shreedhar B, Mohanty L, Shenoy S, Swaminathaa U (2014). Origin of ameloblastoma from basal cells of the oral epithelium establishing the relation using neuroectodermal markers. J Clin Diagn Res 8(10); ZC 44-47

9. Kleinert R (1991). Immunohistochemical characterization of primitive neuroectodermal tumor and their positive relationship to the stepwise odontogenic development of the central nervous system. Acta Neuropathol 82; 508-515
10. Miettinen M (1987). Synaptophysin and neurofilament proteins as a marker for neuroendocrine tumors. Arch Pathol Lab Med 111(9); 813-818

11. Wiedenmann B, Franke WW, Kuhn C, Moll R, Gould VE (1986). Synaptophysin: a marker for neuroendocrine cells and neoplasms, Proc Natl Acad Sci USA 83(10); 35003504

12. Yener Z, Kiran MM (2002). Undifferentiated ganglioneuroblastoma in a sheep. J Comp Pathol 126(2-3); 216-219

13. Meurer RT, Martins DT, Hilbig A, Riberro Mde C, Roehe AV, Barbosa-CoutinhoLM, Fernandes Mda C (2008). Immunohistochemical expression of markers Ki-67, neun, synaptophysin, P53 and HER2 in medulloblastoma and its correlation with clinicopathological parameters. Arq Neuropsiquiatr 66(2B); 285-290

14. Park SG, Park CG, Kim S, Jang S, Chi HS, Kim MJ, Im HJ, Seo JJ (2010). Detection of bone marrow metastasis of neuroblastoma with immunohistochemical staining of CD56, chromogranin A and synaptophysin. Appl Immunohistochem Mol Morphol 15(4); 438-452

15. Kanehira K, Khoury T (2011). Neuroendocrine markers in pancreatic serous cystadenoma Appl Immunohistochem Mol Morphol 19(2); 142-146

16. Annaratone L, Medico E, Rangel N, Castellcino I, Marchio C, Sapino H, Bussolati G (2014). Search for neuroendocrine markers (chromogranin A, synaptophysin and VGF) in breast cancers. An integrated approach using immunohistochemistry and gene expression. Endocr Pathol 25(3); 219-228

17. Gardner David G (1996). Some current concepts on the pathology of ameloblastomas. Oral Surg Oral Med Oral Pathol Oral Radiol Endod 82; 660-669

18. Dandriyal R, Gupta A, Pant S, Baweja HH (2011). Surgical management of ameloblastoma: Conservative or radical approach. Natl J Maxillofac Surg 2(1) ; 22-27

19. Jaafari-Ashkavandi Z, Dehaghani-Nazhvani A, Razmjouyi F (2014). CD56 expression in odontogenic cysts and tumors. J Dent Res Dent Clin Dent Prospect 8(4); 240-245

20. Gagai E, Deligianni E, Antniades DZ, Goode R (2005). Neuroendocrine markers in ameloblastoma-An immunohistochemical study of thirty two cases. Oral Surg Oral Med Oral Pathol Oral Radiol Endod 100(2); 194 